\title{
Microbiological Profile of Urinary Tract Infections with special Reference to Antibiotic Susceptibility Pattern of Escherichia coli Isolates
}

\author{
Eman Elsayed Hegazy ${ }^{*}$, Rasha Abd El-Hamid Alam El-Din ${ }^{1}$, Ahmed Mostafa Amin ${ }^{1}$, \\ Fawkia Mohamed Mahgoub ${ }^{1}$ and Samir Abd El-Hakeem El-Gamal ${ }^{2}$ \\ ${ }^{1}$ Department of Medical Microbiology and Immunology, Faculty of Medicine, \\ Tanta University, Egypt \\ ${ }^{2}$ Urology Department, Faculty of Medicine, Tanta University, Egypt \\ *Corresponding author
}

\begin{tabular}{|l|}
\hline Ke y w o r d s \\
Urinary tract \\
infections \\
$\begin{array}{l}\text { Uropathogenic E. coli, } \\
\text { Antimicrobial } \\
\text { resistance, Antibiotic } \\
\text { susceptibility, } \\
\text { Antibiotic stewardship }\end{array}$ \\
\hline Article Info \\
\hline $\begin{array}{l}\text { Accepted: } \\
\text { 10 January } 2018 \\
\text { Available Online: } \\
\text { 10 February } 2018\end{array}$ \\
\hline
\end{tabular}

\section{Introduction}

Urinary tract infections (UTIs) are a standout amongst the most widely recognized bacterial infections in hospital and community based setting around the world (Maleki et al., 2017). This infection is applied to a variety of clinical conditions ranging from asymptomatic
Urinary tract infections, caused by multidrug resistant uropathogenic Escherichia coli (UPEC) are alarmingly escalating. Widespread utilization of empirical antibiotics without performing anti-microbial susceptibility testing led to expanding resistance to different classes of antimicrobial agents generally prescribed among UPEC isolates in our country. Therefore, this study aims to detect the prevalence and the antibiotic susceptibility pattern of UPEC isolates, in Tanta University Hospitals, Egypt. A total of 200 urine samples were collected from July 2015 to August 2016. Urine count and culture were done. Antibiotic susceptibility testing was performed according to the clinical and laboratory standards institute guidelines (CLSI 2016). E. coli was the predominant isolate (53.85\%) followed by Klebsiella spp. (17.58\%), Candida spp (10.99\%), Proteus spp. (6.04\%) Coagulase negative Staphylococcus (3.85\%) Enterococcus spp. (2.75\%), Pseudomonas spp. (2.19\%), Acinetobacter baumannii (1.65\%), Enterobacter spp. (0.55\%) and Serrate marascences $(0.55 \%)$. The highest percentage of UPEC isolates were non susceptible to Ampicillin, Cefazolin (100\%) for each, followed by Nalidixic acid (91.84\%), Trimethoprim/sulfamethoxazole $(87.9 \%)$, Norfloxacin $(82.65 \%)$, beta-lactam inhibitors (81.3\%), Ceftriaxone (79.60\%), Cefotaxime (74.49\%), Ceftazidime (64.3\%), Gentamicin $(26.53 \%)$, Amikacin (22.45\%), Nitrofurantoin (21.4\%) and Imipenem (20.41\%). Therefore, physicians must follow antibiotic stewardship and change their treatment pattern based on performing antibiotic susceptibility testing. 
Escherichia coli is the most widely recognized Gram-negative extra intestinal pathogen isolated from urine culture in patients with UTIs, whether complicated or uncomplicated, accounting for 70-80 \% of communityacquired infections and 40- $60 \%$ of healthcare-associated infections (Hisano et al., 2015). Uropathogenic Escherichia coli (UPEC) utilize a variety of virulence factors such as surface structural components, like lipopolysaccharide, capsule, flagella, pili, outer membrane proteins, as well as secreted toxins and siderophore. Consequently, these mechanisms are double edged weapon as they play an important role in UTI pathogenesis furthermore; they are attractive candidates for the development of new drugs and vaccines (Werneburg et al., 2015 \& O'Brien et al., 2016).

Worldwide, Antimicrobial resistance among UPEC is a major health concern because of its expanding resistance to different classes of antimicrobial agents generally prescribed (Polse et al., 2016).

The increasing resistance to several broadspectrum antibiotics, utilized in the treatment of UTIs, for example (ampicillin, trimethoprim/sulfamethoxazole, fluoro quinolons, and cephalosporin), among clinical UPEC strains complicates treatment, increases costs, and decreases the effectiveness of the available antibiotics against this infection (Biedenbach et al., 2016).

Hospitalized patients in urology department have a tendency to acquire UPEC infections with higher antimicrobial resistance (Lavigne et al., 2016).

The proper selection of empirical antimicrobials and the effectiveness of antibiotic treatment necessitate a good understanding of the typical bacteriology involved in UTIs as well as the local resistance patterns, and the specific patient's antimicrobial and microbiologic history (Bartoletti et al., 2016).

Studies show that the physicians prescribe antibiotics such as trimethoprim/ sulfamethoxazole, cephalosporins and fluoroquinolones in spite of the expanding bacterial resistance to these drugs (Schmiemann et al., 2012).

There is limited information about the antibiotic resistance patterns among UPEC isolates in our hospital. Therefore, this study aims to detect the prevalence and antibiotic susceptibility patterns of UPEC strains isolated from patients admitted to the urology department in Tanta university hospitals.

\section{Materials and Methods}

This study was carried out on 200 patients (100 inpatients and 100 outpatients) showing clinical pictures of urinary tract infections admitted to the Urology Department and outpatient urology clinics in Tanta University Hospitals, during the period of research from July 2015 till August 2016.

The study incorporated patients who admitted to the hospital and were supposed to have UTI and who gave their informed consent.

Ethical approval for this study was provided by ethics and research committee, Faculty of Medicine, Tanta University.

\section{Collection of samples}

Clean-catch midstream urine was collected into a wide mouth sterile container. Proper instructions were given to the patients regarding the method of collection. Later samples were labeled with patient's age and sex on container. The samples were transported to the laboratory of microbiology 
and processed within 30 minutes for isolation and identification of the causative pathogens.

\section{Urine count}

Semi quantitative culture of urine samples on Cysteine lactose electrolyte deficient (CLED) agar (Oxoid, UK) was used for diagnosis of significant bacteruria or candiduria. The semi quantitative culture was done by inoculating a loopful $1 \mu l$ of well mixed uncentrifuged urine using a sterile calibrated bacteriological loop on CLED agar by surface streak method and colonies were counted after overnight incubation at $37^{\circ} \mathrm{c}$ aerobically. The number of colonies obtained was multiplied by 1000 to obtain the CFU/mL.

The significant colony count is a pure growth of $\geq 10^{5} \mathrm{CFU} / \mathrm{mL}$ in case of bacteriuria and $\geq 10^{4} \mathrm{CFU} / \mathrm{mL}$ in case of candiduria (Collee et al., 2006).

\section{Isolation and identification of uropathogens}

Cultures of urine samples were done for cases with significant urine count; these cultures were done on blood, MacConkey's agars and sabouraud dextrose (Oxoid, UK). The plates were inoculated using a sterile bacteriological loop then all plates were incubated aerobically at $37^{\circ} \mathrm{c}$ for $24 \mathrm{hrs}$ (Cheesbrough, 2006).

The produced colonies were identified by the traditional microbiological methods including microscopic examination, culture characteristics and biochemical reactions for detection of the causative organisms UPEC isolates were confirmed by using integral system enterobatteri (Liofilchem Italy), which is a 24-well system containing desiccated biochemical and antibiotic substrates for the biochemical identification and susceptibility testing of enterobacteria. Briefly the system was inoculated with the bacterial suspension of the micro-organism under examination and incubated at $36^{\circ} \mathrm{C} \pm 1{ }^{\circ} \mathrm{C}$ for $18-24$ hours. The tests for identification and for the susceptibility testing are interpreted by assessing the change in color of the various wells additionally antimicrobial susceptibility profile was confirmed by disk diffusion method.

\section{Antimicrobial susceptibility testing for $E$. coli isolates}

\section{Kirby-Bauer disc diffusion method}

Antibiotic susceptibility testing of the UPEC isolates were done by Kirby-Bauer disc diffusion method using Clinical Laboratory Standards Institute guidelines (CLSI, 2016) criteria on Muller-Hinton agar (Oxoid, UK).

In this study 7 groups of antibiotics were used which were quinolones, cephalosporins, aminoglycosides, aminopenicillin, carbapenes, sulfonamides and nitrofurantoin.

The used antibiotics discs (Oxoid, UK) were Amikacin $\quad(30 \mu \mathrm{g}), \quad$ Gentamicin $\quad(10 \mu \mathrm{g})$, Trimethoprim / Sulfamethoxazole (1.25/23.75 $\mu \mathrm{g})$, Cefazolin $(30 \mu \mathrm{g})$, Cefotaxime $(30 \mu \mathrm{g})$, Imipenem $(10 \mu \mathrm{g}), \quad$ Ampicillin $(10 \mu \mathrm{g})$, Cefoxitin $(30 \mu \mathrm{g})$, Ceftriaxone $(30 \mu \mathrm{g})$, Ceftazidime $(30 \mu \mathrm{g})$ Cepfime $(30 \mu \mathrm{g})$, Nitrofurantoin (300 $\mu \mathrm{g})$, Amoxicillin /

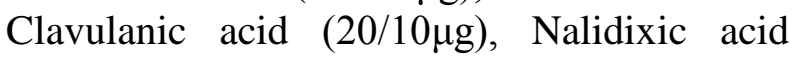
$(30 \mu \mathrm{g})$ and Norfloxacin $(10 \mu \mathrm{g})$.

American Type Culture Collection (ATCC) strain E. coli. ATCC 25922 was used as quality control strain in antimicrobial susceptibility testing.

\section{Statistical analysis}

Data were analyzed using IBM SPSS software package version 20.0(Armonk, NY: IBM Corp) Qualitative data were described using number and percent. The Kolmogorov- 
Smirnov test was used to verify the normality of distribution Quantitative data were described using range (minimum and maximum), mean, standard deviation and median. Significance of the obtained results was judged at the $5 \%$ level.

\section{Results and Discussion}

\section{Characteristics of study participants}

Table 1 gives demographic data and clinical characteristics of the study population. The patient ages ranged between 24 and 65 years with mean \pm SD of age $47.49 \pm 9.26$. Of 200 cases, $73(36.5 \%)$ were male and $127(63.5 \%)$ were female.

As regard to the risk factors for UTIs, urinary stones $(60.0 \%)$, diabetes $(36.3 \%)$ and prostatic hyperplasia $(11.1 \%)$ were the important risk factors for developing UTI other risk factors were nephropathy $(8.1 \%)$, cancer bladder (5.9\%), cancer prostate $(4.4 \%)$, renal failure (4.4\%) and hydronephrosis (3.0\%). (21.5\%) of patients were suffered from hypertension, ascites, cholangiocarcinoma, hepatic encephalopathy and cancer colon.

\section{Prevalence and distribution of uropathogens}

The urine count of 200 urine samples on CLED agar yielded a total of $172(86.0 \%)$ significant bacterial growths including 162 (94.19\%) (Single organism) and $10(5.81 \%)$ mixed infection (Two organisms).

The 172 culture positive samples of urine yielded 182 bacterial isolates including both single growth (162) and mixed growths (10) of two organisms each. Aerobic Gramnegative bacteria were the dominant pathogens $\quad(\mathrm{n}=150 ; \quad 82.42 \%)$ Enterobacteriaceae are the predominant pathogens $(\mathrm{n}=143 ; 78.57 \%)$, while $7(3.85 \%)$ strains belonged to the non-fermenting rods (Pseudomonas aeuroginosa and Acinetobacter baumannii). Gram-positive cocci (Enterococcus spp and Coagulase negative Staphylococcus) were isolated from 12 patients and accounted for $6.6 \%$ of all the isolates. Regarding to fungal infection, Candida was isolated from 20 patients accounting $(10.99 \%)$ as shown in table 2 .

E. coli was the predominant isolate $(53.85 \%)$ followed by Klebsiella spp. (17.58\%), Candida spp (10.99\%), Proteus spp. (6.04\%) Coagulase negative Staphylococcus (3.85\%) Enterococcus spp. (2.75\%), Pseudomonas spp. (2.19\%), Acinetobacter baumannii (1.65\%), Enterobacter spp. $(0.55 \%)$ and Serrate maracences $(0.55 \%)$.Mixed infection showed combination of E. coli and Klebsiella spp in 3 cases. E. coli and Candida in 1 case Klebsiella and Candida in 2 cases. Candida and Enterococcus spp in 2 cases. E. coli and Acinetobacter baumannii in 2 cases respectively.

\section{Antibiotic susceptibility pattern of UPEC isolates}

According to the antibiogram of the isolated UPEC by disc diffusion method, The highest percentage of UPEC isolates were resistant to Ampicillin, Cefazolin (100\%) for each, followed by Nalidixic acid (91.84\%),Trimethoprim/sulfamethoxazole (87.9\%), Norfloxacin $(82.65 \%)$ and betalactam inhibitors (81.3\%), Ceftriaxone (79.60\%), Cefotaxime (74.49\%), Ceftazidime (64.3\%), Gentamicin (26.53\%), Amikacin $(22.45 \%)$, Nitrofurantoin $(21.4 \%)$ and Imipenem (20.41\%) as shown in table 3.

In the current study, regarding age distribution, a higher frequency of UTIs was in the age 24 to 65 years. The mean \pm SD was $47.49 \pm 9.26$ years. 
Our result is inconsistent with the study of (Lavigne et al., 2016) who found that the mean \pm SD of age of UTI cases was $65.8 \pm$ 18.2 years this difference may be attributed to the difference in selection of patients.

Female are more liable to develop UTI than males. This result is in accordance with other studies showed that females have a higher frequency of UTI compared to males (Salunke and Gidamudi, 2017; Mangal et al., 2017) reported similar finding.

Females are more susceptible to UTI because of anatomical reasons or other host factors. The anatomical site of the urogenital tract in females is in charge of bacterial contaminations caused by both internal and external flora (Shanthi and Kayathri, 2012). Diagnosis of UTIs is a good example of the need for close collaboration between the clinician and the microbiologist.

In the present study, the prevalence of UTI was $86.0 \%$. This result is in agreement with the study of (Moue et al., 2015) who reported that prevalence rate of isolation of UTI was $79.5 \%$.

Our result also more or less correlates with the study of (Haque et al., 2015) who found that, the prevalence of UTIs was $59.67 \%$ (including $94.41 \%$ unimicrobial and $5.59 \%$ mixed infection by two organisms).

In comparison to our result; (Pratap et al., 2016) found that prevalence rate of UTI was $32.5 \%$.

This difference may be attributed to the difference in the transport of samples, in the number of selected cases, the media selection and local prevalence rate. Furthermore, general condition of the patients, even the standard personal hygiene and education status may be responsible.
The current study observed aerobic Gramnegative bacteria were the dominant pathogens with Enterobacteriaceae the predominant pathogens

This finding was in agreement with previous studies study done by (Stefaniuk et al., 2016; Kumar et al., 2016 b) in which similar results were reported.

E. coli was the predominant isolate followed by Klebsiella spp. Candida spp, Proteus spp., Coagulase negative Staphylococcus, Enterococcus spp., Pseudomonas spp., Acinetobacter baumannii, Enterobacter spp., and Serrate marascences

This result is in agreement with the previous studies of (Salunke and Gidamudi, 2017; Sanjee et al., 2017; Vranic et al., 2017; Wong et al., 2017) in which similar organisms were isolated, with E.coli was the most prevalent isolate

The highest rate of isolation of $E$. coli causing UTI may be attributed to most of the bacterial organisms causing UTI originate from the faecal flora and among these facultative anaerobes, E. coli constitutes the major portion superimposed by various virulence factors that facilitate the ascent of bacteria from faecal flora, up the urethra into the bladder They have several factors responsible for their attachment to uroepithelium such as adhesins, pili and fimbriae (Das et al., 2006). According to the antibiogram of the isolated UPEC The highest percentage of UPEC isolates were resistant to ampicillin, and cefazolin $(100 \%)$ for each, followed by trimethoprim/sulfamethoxazole $(87.9 \%)$, betalactam inhibitors $(81.3 \%)$, ceftriaxone $(79.60 \%)$, cefotaxime $(74.49 \%)$, ceftazidime $(64.3 \%)$. The higher rate of sensitivity among UPEC isolate were towards amikacin $(77.55 \%)$, imipenem $(76.53 \%)$, nitrofurantoin $(75.5 \%)$ and gentamicin $(71.43 \%)$. 
Table.1 Demographic data and clinical characteristics of studied group of suspected UTIs $(n=200)$

\begin{tabular}{|c|c|c|c|c|}
\hline Demographic data & $\begin{array}{c}\text { Outpatients } \\
\text { (100) }\end{array}$ & $\begin{array}{c}\text { Inpatients } \\
(\mathbf{1 0 0})\end{array}$ & $\begin{array}{c}\text { Total } \\
(n=200)\end{array}$ & $\begin{array}{c}\mathbf{P} \\
\text { Value }\end{array}$ \\
\hline \multicolumn{5}{|l|}{ Sex } \\
\hline Male & $20(20 \%)$ & $53(53 \%)$ & $73(36.5 \%)$ & \multirow[t]{2}{*}{$\mathrm{X}^{2} \mathrm{p}<0.001^{*}$} \\
\hline Female & $80(80 \%)$ & $47(47 \%)$ & $127(63.5 \%)$ & \\
\hline \multicolumn{5}{|l|}{$\operatorname{Age}(\mathbf{y})$} \\
\hline Min.-Max. & $24.0-56.0$ & $40.0-65.0$ & $24.0-65.0$ & \multirow[t]{2}{*}{${ }^{\mathrm{t}} \mathrm{p}<0.001 *$} \\
\hline Mean \pm SD & $42.03 \pm 7.96$ & $52.96 \pm 6.97$ & $47.49 \pm 9.26$ & \\
\hline \multicolumn{5}{|l|}{ Antibiotic intake } \\
\hline Yes & $58(58 \%)$ & $100(100 \%)$ & $158(79 \%)$ & \multirow[t]{2}{*}{$\mathrm{X}^{2} \mathrm{p}<0.001^{*}$} \\
\hline No & $42(42 \%)$ & $0(0 \%)$ & $42(21 \%)$ & \\
\hline \multicolumn{5}{|l|}{ Underlying risk factors } \\
\hline Yes & $35(35 \%)$ & $100(100 \%)$ & $135(67.5)$ & \multirow[t]{2}{*}{$\mathrm{X}^{2} \mathrm{p}<0.001^{*}$} \\
\hline No & $65(65 \%)$ & $0(0 \%)$ & $65(32.5)$ & \\
\hline $\begin{array}{c}\text { Culture result } \\
\text { Significant growth } \\
\text { Non-significant growth }\end{array}$ & $\begin{array}{l}90(90.0 \%) \\
10(10.0 \%)\end{array}$ & $\begin{array}{l}82(82.0 \%) \\
18(18.0 \%)\end{array}$ & $\begin{array}{c}172(86.0 \%) \\
28(14.0 \%)\end{array}$ & $X^{2} p=0.103$ \\
\hline
\end{tabular}

$\mathrm{X}^{2} \mathrm{p}: \mathrm{p}$ values for Chi square test, ${ }^{\mathrm{t}} \mathrm{p}: \mathrm{p}$ values for Student $\mathrm{t}$-test $*$ : Statistically significant at $\mathrm{p} \leq 0.05$ and highly significant at $\mathrm{p} \leq 0.001^{*}$

Table.2 Distribution of uropathogens isolated from positive urine culture of both group

\begin{tabular}{|c|c|c|c|c|c|}
\hline \multicolumn{2}{|c|}{ Organism in UTIs } & \multirow{2}{*}{$\begin{array}{c}\begin{array}{c}\text { No. of } \\
\text { isolates } \\
(\mathbf{n}=\mathbf{1 8 2}) \%\end{array} \\
98 \\
(53.85 \%)\end{array}$} & \multirow{2}{*}{$\begin{array}{l}\begin{array}{c}\text { Outpatients } \\
(\mathbf{n}=90) \mathbf{N} \%\end{array} \\
56(62.22 \%)\end{array}$} & \multirow{2}{*}{$\begin{array}{l}\text { Inpatients } \\
(\mathbf{n}=92) \mathbf{N} \%\end{array}$} & \multirow{2}{*}{\begin{tabular}{|c|}
${ }^{\mathbf{x}} \mathbf{p}$ \\
value \\
0.299 \\
\end{tabular}} \\
\hline \multirow{7}{*}{$\begin{array}{c}\text { Gram -ve } \\
(\mathbf{n}=150) \\
(82.4 \%)\end{array}$} & Escherichia coli & & & & \\
\hline & Klebsiella spp & $32(17.58 \%)$ & $14(15.56 \%)$ & $18(19.56 \%)$ & \\
\hline & Proteus spp & $11(6.04 \%)$ & $3(3.33 \%)$ & $8(8.7 \%)$ & \\
\hline & $\begin{array}{c}\text { Pseudomonas } \\
\text { aeuroginosa }\end{array}$ & $4(2.19 \%)$ & $1(1.11 \%)$ & $3(3.26 \%)$ & \\
\hline & $\begin{array}{c}\text { Acinetobacter } \\
\text { baumannii }\end{array}$ & $3(1.65 \%)$ & $1(1.11 \%)$ & $2(2.17 \%)$ & \\
\hline & Enterobacter spp & $1(0.55 \%)$ & $0(0 \%)$ & $1(1.1 \%)$ & \\
\hline & Serratia marcescens & $1(0.55 \%)$ & $0(0 \%)$ & $1(1.1 \%)$ & \\
\hline \multirow[t]{2}{*}{$\begin{array}{c}\text { Gram +ve } \\
(n=12)(6.6 \%)\end{array}$} & $\begin{array}{l}\text { Coagulase negative } \\
\text { Staphylococcus }\end{array}$ & $7(3.85 \%)$ & $5(5.56 \%)$ & $2(2.17 \%)$ & \\
\hline & Enterococcus & $5(2.75 \%)$ & $2(2.22 \%)$ & $3(3.26 \%)$ & \\
\hline $\begin{array}{c}\text { Fungi }(n=20) \\
(10.99 \%)\end{array}$ & Candida spp. & $20(10.99 \%)$ & $8(8.89 \%)$ & $12(13 \%)$ & \\
\hline \multicolumn{2}{|c|}{ Total } & $182(100)$ & $90(100 \%)$ & $92(100 \%)$ & \\
\hline
\end{tabular}


Table.3 Antibiotic susceptibility of isolated UPEC strains disc diffusion method ( $\mathrm{n}=98)$

\begin{tabular}{|c|c|c|c|c|}
\hline Antibiotics ( $\mu \mathrm{g})$ & Symbol & $\begin{array}{l}\text { Sensitive(mm) } \\
\text { (N) } \%\end{array}$ & $\begin{array}{l}\text { Intermediate } \\
(\mathbf{m m})(\mathbf{N}) \%\end{array}$ & $\begin{array}{c}\text { Resistant(mm) } \\
\text { (N) } \%\end{array}$ \\
\hline Amikacin(30) & $\mathbf{A K}$ & $76(77.55)$ & - & $22(22.45)$ \\
\hline Gentamicin (10) & $\mathbf{C N}$ & $70(71.43)$ & $2(2.04)$ & $26(26.53)$ \\
\hline $\begin{array}{c}\text { Trimethoprim/ } \\
\text { sulfamethoxazole (25) }\end{array}$ & SXT & $9(9.9)$ & $2(2.02)$ & $87(87.9)$ \\
\hline Nitrofurantoin (300mcg) & $\mathrm{F}$ & $74(75.5)$ & $3(3.1)$ & $21(21.4)$ \\
\hline Ampicillin $(10 \mu \mathrm{g})$ & AMP & - & - & $98(100.0)$ \\
\hline Cefazolin $(30 \mu \mathrm{g})$ & $\mathbf{C Z}$ & _- & - & $98(100.0)$ \\
\hline Cefotaxime $(30 \mu \mathrm{g})$ & CTX & $25(25.51)$ & - & $73(74.49)$ \\
\hline Ceftazidime ( $30 \mu \mathrm{g})$ & CAZ & $30(30.6)$ & $5(5.1)$ & $63(64.3)$ \\
\hline Ceftriaxone $(30 \mu \mathrm{g})$ & CRO & $20(20.40)$ & - & $78(79.60)$ \\
\hline Cefoxitin (30g) & FOX & $35(35.71)$ & & $63(64.29)$ \\
\hline Cefepime & FEP & $37(37.76)$ & & $61(62.24)$ \\
\hline $\begin{array}{l}\text { Amoxicillin / clavulanic acid } \\
\qquad(20 / 10 \mu \mathrm{g}) .\end{array}$ & AMC & $24(18.7)$ & - & $74(81.3)$ \\
\hline Imipenem $(10 \mu g)$ & IPM & $75(76.53)$ & $3(3.06)$ & $20(20.41)$ \\
\hline Nalidixic acid & NAL & $8(8.16 \%)$ & 0 & $90(91.84 \%)$ \\
\hline Norfloxacin & NOR & $17(17.35 \%)$ & 0 & $81(82.65 \%)$ \\
\hline
\end{tabular}

The study of (Maleki et al., 2017) found that the UPEC isolates were most resistant to ampicillin $(82.9 \%)$, cefalotin $(78.1 \%)$, and tetracycline $(61.1 \%)$. Antibiotic resistance to cefazolin $(49.5 \%)$, ceftriaxone $(38.2 \%)$, cefotaxime $(30.2 \%)$, ceftazidime $(26.1 \%)$, ciprofloxacin $(42.2 \%)$, and cotrimoxazole $(60.1 \%)$. The isolates were most sensitive to nitrofurantoin $(95.9 \%)$, gentamicin $(77.2 \%)$, and amikacin $(71.5 \%)$

This finding is in agreement with the study of (Thangavel et al., 2017) who reported that the higher rate of sensitivity among UPEC isolate were towards Amikacin (96.3\%), Imipenem (96.3\%), and Nitrofurantoin $(89.7 \%)$. On the other hand, the study of (Chander, 2016) high resistance levels were detected against gentamicin (91.11\%) while Nitrofurantoin recorded the least resistance levels $(13.33 \%)$ among the E. coli isolates.

In comparison to our result (Munkhdelger et $a l ., 2017)$ found that antibiotic resistance was cephalotin $(85.1 \%)$, ampicillin $(78.4 \%)$, and trimethoprim/sulfamethoxazole $(70.9 \%)$ in the UPEC strains. Sensitivity values above $50 \%$ were found to gentamicin $(57.4 \%)$, ciprofloxacin $(58.1 \%)$, ceftazidime $(66.2 \%)$, cefuroxime $(76.4 \%)$, cefoxitin $(93.9 \%)$, nitrofurantoin (94.6\%), and imipenem (98\%).

(Munkhdelger et al., 2017) explained the higher sensitivity rate towards nitrofurantoin due to the lower frequency of the use of this drug. Regarding to resistance to nalidixic acid our result also is in agreement with (Haque et al., 2015) who reported similar result

The susceptibility patterns of E.coli against different antibiotics vary in different geographical regions, eventually leading to empirical therapy which is based on the local susceptibility profiles. Bacterial biofilm are often associated with long-term persistence of organism in various environments. Bacteria in biofilm display dramatically increased resistance to antibiotics (Tajbakhsh et al., 2016).

The highest rate of resistance among UPEC is mainly due to unwise use of antibiotics. The 
increased accessibility of antibiotics probably an important factor in antibiotic resistance, Discontinuation of treatment due to negligence of patient or unavailability of drugs also develops antibiotic resistance (Chander, 2016).

The practice of prescribing antibiotics to treat UTI without bacterial characterization led to increased resistance among uropathogens and to decrease infectiveness of oral therapies. Despite clinical symptoms of UTIs have been ameliorated by numerous antibiotics, UPEC persistence and resistance to antibiotics represent a serious problem (Blango and Mulvey, 2010). Therefore important measures are mandatory to ensure rational and wellinformed use of antibiotics; Antibiotic stewardship should be introduced in clinical practice to avoid the risk of infection episodes in which the urologist cannot risk systemic inflammatory response syndrome or sepsis (Bartoletti et al., 2016).

In conclusion, the high incidence rate of UTIs reported in this study should be of great concern, as not only do UTIs pose a threat to health, but they also impose an economic and social burden. Increasing rate of resistance to commonly used antibiotics is an alarming sign for future of healthcare sector. Injudicious use of antibiotics could be the most important reason for such high rate of increasing resistance. Therefore, empirical treatment should be carefully selected based upon the susceptibility data of isolates as there is variation in antibiotic susceptibility pattern of UPEC. Antimicrobial stewardship has become a highly important measure in the struggle to preserve the effectiveness of available antimicrobials

\section{Acknowledgments}

I would like to express my great thank to the staff of Microbiology laboratory of Infection
Control Unit for their cooperation in the collection of isolates used in this study.

\section{References}

Bartoletti, R., Cai, T., Wagenlehner, F.M., Naber, K. and Johansen, T.E., 2016. Treatment of urinary tract infections and antibiotic stewardship. Eur. Urol Supplements. 15(4):81-88.

Biedenbach, D.J., Badal, R.E., Huang M.Y., Motyl, M, Singhal, P.K., Kozlov, R.S., Roman, A.D. and Marcella, S 2016. In Vitro activity of oral antimicrobial agents against pathogens associated with community-acquired upper respiratory tract and urinary tract infections: a five country surveillance study. Infectious diseases and therapy. 5(2):139-153.

Blango, M.G. and Mulvey, M.A., 2010. Persistence of uropathogenic Escherichia coli in the face of multiple antibiotics. Antimicrob Agents Chemother. 54(5): 1855-1863.

Chander, M.P., 2016. Antibiotic Susceptibility of Uropathogenic E. coli Isolates from Hospitalized Patients in Warangal City. Int. J. Curr. Microbiol. App. Sci. 5(10): 16-19.

Cheesbrough, M., 2006. Chapter seven microbiological tests in district laboratory practice in tropical countries: part II: 2nd edition, Cambridge university press; pp1-266.

Clinical and Laboratory Standards Institute 2016. Performance Standards for Antimicrobial Susceptibility Testing. $26^{\text {th }}$ ed: CLSI supplement M100S: Wayne, PA.

Collee, J.G., Miles, R.S. and Watt, B., 2006. Tests for identification of bacteria. In: Collee JG, Fraser AG, Marmion BP, Simmons A, eds. Mackie and $\mathrm{Mc}$ Cartney Practical Medical Microbiology.14th ed. Singapore. 
Churchill Livingstone; 131-149.

Das, R.N., Chandrashekhar, T.S., Joshi, H.S., Gurung, M., Shrestha, N. and Shivananda, P.G., 2006. Frequency and susceptibility profile of pathogens causing urinary tract infections at a tertiary care hospital in western Nepal. Singapore medical journal. 47(4): p.281.

Haque, R., Akter, M.L. and Salam, M.A., 2015. Prevalence and susceptibility of uropathogens: A recent report from a teaching hospital in Bangladesh. BMC research notes. 8(1): 416.

Hisano, M., Bruschini, H., Nicodemo, A.C., Gomes, C.M., Lucon, M. and Srougi, M., 2015. The bacterial spectrum and antimicrobial susceptibility in female recurrent urinary tract infection: how different they are from sporadic single episodes? Urology. 86(3): 492-497.

Kumar, G.V., George, A. and Viswanathakumar, H.M., 2016a. Study of clinical profile and risk factors associated with febrile urinary tract infection in preschool children. Int. J. of Contemp Pediatr. 3(1):243-246.

Kumar, S., Budhani, D. and Sayal, P., 2016 b. Bacterial Uropathogens and Empirical Treatment in Urinary Tract Infection in a Tertiary Care Institute. Int. J. Curr. Microbiol. App. Sci. 5(4):47-54.

Lavigne, J.P., Bruyère, F., Bernard, L., Combescure, C., Ronco, E., Lanotte, P., Coloby, P., Thibault, M., Cariou, G., Desplaces, N. and Costa, P. 2016. Resistance and virulence potential of uropathogenic Escherichia coli strains isolated from patients hospitalized in urology departments: a French prospective multicentre study. J. Med. Microbiol. 65(6):530-537.

Maleki, D., Jahromy, S.H., Karizi, S.Z. and Eslami, P., 2017. The prevalence of acrA and acrB genes among multipledrug resistant uropathogenic
Escherichia coli isolated from patients with UTI in Milad Hospital, Tehran. Avicenna. J. Clin. Microb. Infec. 4(1).

Mangal, N., Vyas, A., Kumar, M. and Dalal, A.S., 2017. Antibiogram of Escherichia coli Isolates from Community Acquired Urinary Tract Infection: Special Reference to Fluoroquinolones Resistance. Int. J. Curr. Microbiol. App. Sci. 6(7): 22-31.

Moue, A., Aktaruzzaman, S.A., Ferdous, N., Karim, M.R., Khalil, M.M. and Das, A.K., 2015.Prevalence of urinary tract infection in both outpatient department and in patient department at a medical college setting of Bangladesh. International Journal of Biosciences. 7(5): 146-152.

Munkhdelger, Y., Gunregjav, N., Dorjpurev, A., Juniichiro, N. and Sarantuya, J., 2017. Detection of virulence genes, phylogenetic group and antibiotic resistance of uropathogenic Escherichia coli in Mongolia. The Journal of Infection in Developing Countries. 11(01):51-57.

O'Brien, V.P., Hannan, T.J, Nielsen, H.V. and Hultgren, S.J., 2016. Drug and vaccine development for the treatment and prevention of urinary tract infections. Microbiology Spectrum. 4(1):1-62.

Polse, R.F., Yousif, S.Y. and Assafi, M.S., 2016. Prevalence and antimicrobial susceptibility patterns of uropathogenic E. coli among people in Zakho, Iraq. International Journal of Research in Medical Sciences. 4(4): 1219-1223.

Pratap, R., Kumar, A. and Aslami, A.N., 2016. Prevalence and Antibiotic Susceptibility Pattern of Escherichia coli Positive Urinary Tract Infections in a Rural Tertiary Care Hospital in Rohtas, Bihar, India. Int. J. Curr. Microbiol. App. Sci. 5(10): 128-134.

Salunke, G.V., and Gidamudi, S.S., 2017. Antibiotic Susceptibility of bacterial 
strains with special reference to Escherichia coli isolated from urinary tract infections in rural Maharashtra. Asian J Pharm Clin Res. 10(1):202-205. Sanjee, S.A., Karim, M.E., Akter, T., Parvez, M.A.K., Hossain, M., Jannat, B. and Pervin, S., 2017.Prevalence and Antibiogram of Bacterial Uropathogens of Urinary Tract Infections from a Tertiary Care Hospital of Bangladesh. Journal of Scientific Research. 9(3): 317-328.

Schmiemann, G., Gágyor, I., HummersPradier, E. and Bleidorn, J., 2012. Resistance profiles of urinary tract infections in general practice-an observational study. BMC urology. 12(1): 33 .

Shanthi, J., and Kayathri, S. 2012. Incidence, distribution and antibiogram of uropathogens isolated from patients with urinary tract infections. Adv Applied Sci Res.3:3410-3414.

Stefaniuk, E., Suchocka, U., Bosacka, K. and Hryniewicz, W., 2016. Etiology and antibiotic susceptibility of bacterial pathogens responsible for communityacquired urinary tract infections in Poland. Eur J Clin Microbiol Infect Dis. 35(8): 1363-1369.

Tajbakhsh, E., Ahmadi, P., AbedpourDehkordi, E., Arbab-Soleimani, N. and
Khamesipour, F., 2016. Biofilm formation, antimicrobial susceptibility, serogroups and virulence genes of uropathogenic E. coli isolated from clinical samples in Iran. Antimicrob Resist Infect Contro. 5(1): p.11.

Thangavel, S., Maniyan, G., Vijaya, S. and Venkateswaran, $\quad$ C., 2017. Bacteriological Profile of Uropathogens and their Antimicrobial Susceptibility Pattern in Isolates from a Tertiary Care Hospital. Int. J. Curr. Microbiol. App. Sci. 6(5):2279-2286.

Vranic, S.M., Zatric, N., Rebic, V., Aljicevic, M. and Abdulzaimovic, A., 2017. The Most Frequent Isolates from Outpatients with Urinary Tract Infection. Materia socio-medica. 29(1):17.

Werneburg, G.T., Henderson, N.S., Portnoy, E.B., Sarowar, S., Hultgren, S.J., Li, H. and Thanassi, D.G., 2015. The pilus usher controls protein interactions via domain masking and is functional as an oligomer. Nat. Struct Mol Biol. 22(7):540-546.

Wong, C.K.M., Kung, K., Au-Doung, P.L.W., Ip, M., Lee, N., Fung, A. and Wong, S.Y.S., 2017. Antibiotic resistance rates and physician antibiotic prescription patterns of uncomplicated urinary tract infections in southern Chinese primary care. PloS one. 12(5): p. e0177266.

\section{How to cite this article:}

Eman Elsayed Hegazy, Rasha Abd El-Hamid Alam El-Din, Ahmed Mostafa Amin, Fawkia Mohamed Mahgoub and Samir Abd El-Hakeem El-Gamal. 2018. Microbiological Profile of Urinary Tract Infections with special Reference to Antibiotic Susceptibility Pattern of Escherichia coli Isolates. Int.J.Curr.Microbiol.App.Sci. 7(02): 911-920. doi: https://doi.org/10.20546/ijcmas.2018.702.115 